\title{
Commentary: Have a cigar
}

\author{
Gregory D. Rushing, MD, and Nahush A. Mokadam, MD
}

From the Division of Cardiac Surgery, The Ohio State University Wexner Medical Center, Columbus, Ohio. Disclosures: G.D.R. is an investigator for Abbott, Medtronic, and Allergan. N.A.M. is an investigator and consultant for Abbott, Medtronic, and SynCardia.

Received for publication April 9, 2019; accepted for publication April 9, 2019; available ahead of print May 15, 2019.

Address for reprints: Nahush A. Mokadam, MD, Division of Cardiac Surgery, Kakos and Williams Endowed Professor in Cardiac Surgery, N-825 Doan Hall 410 W 10th Ave, Columbus, OH 43210 (E-mail: Nahush. Mokadam@osumc.edu).

J Thorac Cardiovasc Surg 2020;159:218-9

$0022-5223 / \$ 36.00$

Copyright $(2019$ by The American Association for Thoracic Surgery

https://doi.org/10.1016/j.jtcvs.2019.04.032



It is an exciting time to be a structural heart surgeon-we have accomplished something rarely done in medicine before. We have taken a novel disruptive technology, transcatheter aortic valve replacement (TAVR), and brought it to mainstream treatment of patients in a progressive stepwise fashion supported by randomized, controlled trials. In the less than 17 years from the compassionate use of a homemade transcatheter valve to this past month, 2 new trials reported on the use of TAVR in low-risk patient populations. ${ }^{1,2}$ Both of these trials had positive results and met their primary end points, if not all their secondary end points. These trials (in conjunction with their predecessors) have led the US Centers for Medicare and Medicaid Services to propose a new model, doing away with the "two-surgeon" evaluation yet still requiring both the cardiologist and surgeon in the operating room. ${ }^{3}$

In this issue of the Journal, Hage and colleagues ${ }^{4}$ present an article editorializing on the rapidly expanding use of "wire-based" and minimally invasive procedures in the field of cardiovascular surgery. Hage and colleagues ${ }^{4}$ propose more integration of TAVR, as the most common wire-based procedure, for resident education. Their stance is that cardiothoracic residents are behind their cardiology counterparts in being taught "new technology." They recommend the use of percutaneous boot camps and wet labs to make the residents more skilled when attending these procedures. As structural heart surgeons know well, attendance at multidisciplinary committee meetings and participation in outpatient clinics help the providers understand patient, valve, and access selection. Residents currently struggle with competing interests and have generally poor participation in these broader aspects of patient care, making it less likely that the cardiothoracic resident will be involved in the conduct of these procedures. Hage and colleagues ${ }^{4}$ are correct that technology is altering what our residents need to learn. The shifting treatment of

severe aortic stenosis will modify their training and how they prioritize their own educational goals. But the world is not ending.

Technology is undoubtedly changing our field, but it is not removing our relevance. Similar to the inaccuracy of claims of the "death of cardiac surgery" after the introduction percutaneous coronary interventions, cardiothoracic surgeons will still be needed after low-risk TAVR is approved. In most programs, surgical valve volumes are stable as the number of TAVR cases continues to rise. Residents must embrace this change and actively seek opportunities to maintain their ownership of the TAVR patient along the entire spectrum of care. At the same time, although more patients will be referred for TAVR, those with low-lying coronary arteries, enlarged annuli, small aortic roots, and bicuspid aortic valves will all require surgical intervention. And we have yet to see the impending wave of surgical TAVR removals as we enter the phase of long-term structural valve degeneration. Severe aortic stenosis will still entail a team of surgeons and cardiologists working together. These teams are already utilizing new bioengineering technology, which will soon enable individual patient specific planning. ${ }^{5,6}$ We may even create new indications for valve replacement, such as heart failure and moderate aortic stenosis. Surgeons are busier than ever!

The future practice of our residents is different, and certainly bright. "You're gonna fly high, you're never gonna 
die. You're gonna make it if you try...they're gonna love you!"7

\section{References}

1. Mack MJ, Leon MB, Thourani VH, Makkar R, Kodali SK, Russo M, et al; Partner 3 Investigators. Transcatheter aortic-valve replacement with a balloon-expandable valve in low-risk patients. $N$ Engl J Med. 2019;380:1695-705.

2. Popma JJ, Deeb GM, Yakubov SJ, Mumtaz M, Gada H, O'Hair D, et al; Evolut Low Risk Trial Investigators. Transcatheter aortic-valve replacement with a self-expanding valve in low-risk patients. N Engl J Med. 2019;380:1706-15.

3. Center for Medicare and Medicaid Services. Proposed decision memo for transcatheter aortic valve replacement (TAVR) (CAG-00430R). Available at: https://www.cms.gov/medicare-coverage-database/details/nca-proposed-decisionmemo.aspx?NCAId=293. Accessed August 4, 2019.

4. Hage A, Hage F, Chu MW. Cardiac surgery residency and transcatheter aortic valve replacement: "What happened to my aortic valve replacement?" J Thorac Cardiovasc Surg. 2020;159:215-7.

5. Hatoum H, Dollery J, Lilly S, Crestanello J, Dasi LP. Impact of patient-specific morphologies on sinus flow stasis in transcatheter aortic valve replacement: an in vitro study. J Thorac Cardiovasc Surg. 2018;157:540-9.

6. Heitkemper M, Hatoum H, Azimian A, Yeats B, Dollery J, Whitson B, et al. 3D computational model to predict coronary obstruction during TAVR. JACC Cardiovasc Interv. 2019;12:S43-4

7. Waters R, composer, Pink Floyd, artist. Have a Cigar [music recording]. New York: Sony Music Entertainment; 1975. 